\title{
Factors Affecting Adoption of BRRI Released Aus Rice Varieties in Mymensingh District
}

\author{
Md. Shajedur Rahaman*, Md. Jahangir Kabir, Md. Abdur Rouf Sarkar, Mohammad Ariful Islam, \\ Mohammad Chhiddikur Rahman, Md. Abu Bakr Siddique
}

Agricultural Economics Division, Bangladesh Rice Research Institute (BRRI), Gazipur, Bangladesh

\section{Email address:}

saju021@gmail.com (Md. S. Rahaman),jkabirbrri@yahoo.com (Md. J. Kabir),mdrouf_bau@yahoo.com (Md. A. R. Sarkar), arifagecon@gmail.com (M. A. Islam), siddiquer07@gmail.com (M. C. Rahman), abs_63@yahoo.com (Md. A. B. Siddique)

${ }^{*}$ Corresponding author

\section{To cite this article:}

Md Shajedur Rahaman, Md Jahangir Kabir, Md Abdur Rouf Sarkar, Mohammad Ariful Islam, Mohammad Chhiddikur Rahman, Md Abu Bakr Siddique. Factors Affecting Adoption of BRRI Released Aus Rice Varieties in Mymensingh District. International Journal of Agricultural Economics. Vol. 5, No. 5, 2020, pp. 210-217. doi: 10.11648/j.ijae.20200505.18

Received: July 17, 2020; Accepted: July 29, 2020; Published: October 12, 2020

\begin{abstract}
This study was carried out to evaluate the performance of BRRI cultivars, identifying criteria and constraints as well as factors influencing the intensity of BRRI cultivars adoption in Aus season on the farm households in Mymensingh district. The data were collected through structured questionnaires from a total of 390 randomly selected rice farmers from thirteen Upazila of Mymensingh district. The study employed descriptive statistics and Tobit censored regression to determine the adoption and yield status; and adoption intensity determinants. In addition to a total of thirteen FGDs and expert panel interview was conducted to verify the collected data. The results show that 82.04 percent of the area in Mymensingh district was cultivated with rice variety developed by Bangladesh Rice Research Institute (BRRI) with an average yield of $4.05 \mathrm{t} / \mathrm{ha}$ during the Aus season. The findings of the Tobit censored regression indicate that schooling, distance to the local market, training, price variation, taste and preference, amount of cultivated varieties, yield variability were the significant factors of the intensity of BRRI varieties adoption in Aus season. The study's results suggested that breeders should also emphasize the choice of farmers while developing varieties. In addition to developing new rice varieties, BRRI, Department of Agricultural Extension (DAE), Bangladesh Agricultural Corporation (BADC) and other seed producing organizations need to work together to provide the farmers with good quality seeds of BRRI varieties, which will increase the total production of the country, thus helping to ensure food safety.
\end{abstract}

Keywords: Adoption Intensity, Aus Season, BRRI Varieties, Tobit Censored Regression, Criteria and Constraints, Rice, Bangladesh

\section{Introduction}

Among the major challenges facing Bangladesh are sustainable food production and ensuring food security for all. A major issue for Bangladesh has been and will continue to be food safety [1]. The government of Bangladesh is working tirelessly to ensure food security for all. Despite steady progress towards industrialization, agriculture remains the most important sector in Bangladesh. The agriculture sector is fully cooperating with the government of Bangladesh to achieve food self-sufficiency and food security. The agriculture sector contributed 13.64 percent of total Gross Domestic Product (GDP), employing $40 \%$ of the population and seems to have managed to feed around 164.6 million people of the country $[2,3]$. Rice plays the leading role in all crops by contributing to 88.33 percent of the overall output of food grain [2].

Rice is Bangladeshi's staple food as it is consumed @367 $\mathrm{gm} /$ person/day by 99 percent of the population, supplying around 75 percent of the calories and 55 percent of the protein in the average daily diet [4-6]. Although steady rice supply has significant consequences for food security, many see food security as associated with achieving selfsufficiency in rice production [7]. Rice has occupied about 
74.85 percent of the total crop area and produced 36.39 million tons of rice [2]. Rice cultivated in Bangladesh in three overlapping seasons namely, Aus, Aman, and Boro [8]. Besides two other rice crops (Aman and Boro), Aus rice contributed to food production until the mid-1980s. Aus is usually grown in March-April and harvested in June-July. Aus rice accounts for nearly 9.59 percent of the overall cultivated area, covering 84.59 percent of modern varieties, producing 2.70 million tons of clean rice [2].

Uddin and Dhar noted that Aus rice started to lose its value as farmers gradually began to move to irrigated Boro rice cultivation supported by its higher yields [9]. The acreage dwindled below 1.5 million hectares now during the Aus season, from 3.0 million hectares in the early $1980 \mathrm{~s}$, and rice output slumbered as well. Simultaneously, the Boro rice acreage and production went up many folds. On the other side, climate change would possibly affect Bangladesh's Aus rice production. Research indicates that any period from seedling to reproductive stages $A u s$ rice may be suffering from drought [10]. Khanom displayed evidence of decreased Aus yield in a warmer (by $4^{0} \mathrm{C}$ ) temperature scenario [11]. Since the advent of modern technology and best management practices, the farmers have altered the cropping patterns as well as farming systems. Farmers have also modified their pattern of land use under this farming circumstance and launched a mix of modern ventures along with rice production [12]. As a result, there has been a shift to $A u s$ rice land and the production of jute [13]. BRRI indicates that one of the factors behind the decrease in the production of Aus rice is the non-availability of land as its seed sowing or transplanting cycle falls during March and April while Boro rice remains in the region [14]. Farmers do not get adequate time and land to produce paddy out of it.

On the other side, the increasing population of the country by 2050 need to generate an additional 10.8 million tons of rice to fulfill food grain demand [15]. Sustaining the food security status and supplying additional food for the country's ever-growing population from dwindling land and other scared resources, thus, presents a major challenge [16]. Governments are therefore intervening in agriculture to achieve a wide range of economic and social goals and achieve food security. Agricultural incentives are a common element in agricultural development, to promote the adoption of new technologies and thus increase the productivity of agriculture [17]. This intervention can take several forms such as price support programs, direct payments, and input support to influence the costs and availability of agricultural inputs such as credit, fertilizers, seeds, irrigation water, etc. Input aid is the most common of all domestic support instruments in agriculture.

Bangladesh's government has, however, launched an incentive program with a Tk (Bangladeshi currency) cost. 336.2 million for small and marginal farmers in the country, seeking to rejuvenate the Aus rice cultivation. In contrast, a total of 231,363 small and marginal farmers were provided with seed and chemical fertilizers at no cost to grow local high yielding variety (HYV) and NERICA (a stress-tolerant
African variety) of Aus rice in 49 drought-prone districts throughout the country [9]. The government of Bangladesh was allocated 350 million Tk. for Aus seeds and fertilizers in 2020, while 360 million Tk was allocated for irrigation to increase the output. These required inputs have already been moved to different stations across the country, and the farmers are getting these inputs for the Aus rice cultivation.

Additionally, public organizations such as the BRRI, Bangladesh Institute of Nuclear Agriculture (BINA), and universities in Bangladesh have been researching for the development and dissemination of modern high-yielding short-duration rice variety. BRRI has so far developed 102 HYV rice varieties including 7 hybrids [18]. Out of 102 varieties, few mega varieties have been popularized and adopted in various seasons, contributing to the selfsufficiency of the rice. BRRI developed Aus rice verities covering about 70.28 percent of the total area of total cultivated areas and produced clean rice of 2.0 million tons. In such a scenario, an in-depth study was undertaken to examine the adoption and yield status of $A u s$ rice varieties, as well as criteria, constraints, and factors influencing the adoption of BRRI developed Aus rice cultivars.

\section{Methodology}

\subsection{Study Area and Sample Size}

The study was conducted at 13 Upazilas of Mymensingh district. All of the Upazilas were selected purposively and thereafter, two Unions from each Upazila were selected randomly for this survey. The survey was conducted from April to July 2018. A total of 390 farmers were randomly selected to identify factors affecting the BRRI developed Aus rice cultivars' adoption decision. Farm-level data were collected with key informants and household surveys through a Farmers' Group Discussion (FGD). Besides, a total of thirteen FGDs were performed to produce in-depth data on the adaptation dynamics of rice varieties at Aus season. An expert panel interview consisting of Sub-Assistant Agriculture Officer (SAAO) and Upazila Agriculture Officer (UAO) was held in order to verify the data gathered via the discussion group of farmers. Using a pre-tested standardized questionnaire, selected farmers were questioned. The data were analyzed using both descriptive and inferential statistics. Descriptive statistics used primarily to analyze the frequency, percentage, mean, and median of the farmers' socioeconomic attributes in the study area. The Tobit model was used to identify the factors behind the adoption of BRRI technology and to analyze the probability of farmers adopting technology and the intensity of adoption.

\subsection{Econometric Model}

The Logit and Probit models are the two popular models used by different research to determine the impact of variables affecting the probability of a given technology being implemented. Adoption experiments focused on dichotomous regression models, however, have sought to 
clarify only the probability of adoption versus non-adoption rather than adoption rate and intensity [19]. For certain problems such as fertilizer, therefore, a purely dichotomous variable is always not adequate to examine the extent and intensity of the adoption [20]. Meanwhile, Splett, et al established what became known as the Tobit or censored regression model for circumstances where dependent variable values greater than 0 are observed but are not observed (censored) at zero or lower values [21]. The Tobit model is also a broad class of models with discrete as well as continuous parts. It is an extension of the Probit model and is one approach to tackling the censored data problem [22].

\subsection{Model Specification}

The Tobit model applied for analyzing factors affecting the adoption of BRRI rice varieties is shown below:

$$
\mathrm{Y}_{\mathrm{i}}^{*}=\beta \mathrm{X}_{\mathrm{i}}+\mu_{\mathrm{i}}, \mathrm{i}=1,2 \ldots \mathrm{n} .
$$

Where,
$\mathrm{Y}_{\mathrm{i}}=$ the observed dependent variable (index of adoption of BRRI rice varieties)

$\mathrm{Y}_{\mathrm{i}}^{*}=$ the latent variable

$\mathrm{X}_{\mathrm{i}}=$ vector of factors affecting adoption and intensity of $\mathrm{BRRI}$ rice varieties

$\beta_{\mathrm{i}}=$ vector of unknown parameters

$\mu_{\mathrm{i}}=$ residuals that are independently and normally distributed with mean zero and a common variance $\left(\sigma^{2}\right)$.

The Tobit model shown above is also called a censored regression model because it is possible to view the problem as one where observation of $\mathrm{Y}^{*}$ at or below zero are censored [22].

\subsection{Definition of Variables}

In this study, the dependent variable is the adoption and intensity of the BRRI rice varieties being adopted. The explanatory variables were taken those variables which are thought to influence the adoption and intensity of BRRI rice varieties.

Table 1. Definition of the variables.

\begin{tabular}{|c|c|c|}
\hline Variables & Description & Expected sign \\
\hline \multicolumn{3}{|l|}{ Dependent variable } \\
\hline $\begin{array}{l}\text { Adoption and intensity of adoption of the BRRI rice } \\
\text { varieties }\end{array}$ & \multicolumn{2}{|c|}{$\begin{array}{l}0 \text { for non-adopters and varied between } 0 \text { and } 1 \text { for adopters (where } 1 \text { mean } 100 \% \text { of BRRI } \\
\text { varieties were adopted) }\end{array}$} \\
\hline \multicolumn{3}{|l|}{ Explanatory variables } \\
\hline \multicolumn{3}{|l|}{ Socio-demographic variables: } \\
\hline Farmers Age & Year & + \\
\hline Education & Year of schooling & + \\
\hline Farm size & Operated area in hectares & + \\
\hline \multicolumn{3}{|l|}{ Access to information: } \\
\hline Training received & Dummy ( $1=$ received training, $0=$ otherwise $)$ & + \\
\hline Distance to local market & Kilometer & - \\
\hline Distance to UAO & Kilometer & - \\
\hline Price variation & $\mathrm{Tk} . / \mathrm{kg}$ & + \\
\hline \multicolumn{3}{|l|}{ Varietal specific characteristics: } \\
\hline Yield variation & $\mathrm{Kg} / \mathrm{ha}$ & + \\
\hline
\end{tabular}

\section{Results and Discussion}

\subsection{Socio-economic Features}

Table 2 illustrates a summary of the socio-economic and demographic information of the sampled respondents in the study area. The table shows that most of the respondents belong to the age group 31 to 39 . The age of farmers plays a crucial position in farming and management practices. Mostly younger farmers are embracing emerging technology more rapidly than their older peers. The average family size was 5.40, of which 48.71 percent male. It was observed that 43.07 percent of respondents were having primary education while 21.10 percent had no formal education. Results also show that 72.56 percent of the respondents had a small farm size, and around 79 percent's primary occupation was farming in the study area. On average 51.02 percent of farmer's farming experience was ranged between 21 to 40 years. The average distance from home to the nearby market, and Upazila Agriculture Office (UAO, respectively, was 4.12 and 5.5 kilometers. Typically around 15 percent of respondents have also been involved as members of various social organizations.

Table 2. Socio-demographic characteristics of the sampled farmers in the study area.

\begin{tabular}{ll}
\hline Particulars & Percentage \\
\hline Age: & \\
<30 years & 15.38 \\
31-39 years & 36.66 \\
41-50 years & 21.28 \\
51 -60 years & 14.10 \\
61 years and above & 12.56 \\
Family size: & \\
1-3 person & 17.17 \\
4-6 person & 57.69 \\
7 and above person & 25.12 \\
Male & 48.71 \\
Female & 51.28 \\
\hline
\end{tabular}




\begin{tabular}{ll}
\hline Particulars & Percentage \\
\hline Education: & \\
No formal education (0) & 24.10 \\
Primary education (i-v) & 43.07 \\
Secondary education (vi-x) & 20.00 \\
Higher secondary Education (xi-xii) & 11.28 \\
Graduate and above & 1.53 \\
Farm classification: & \\
Small & 72.56 \\
Medium & 24.87 \\
Large & 2.56 \\
Occupation: & \\
Farming as primary & 78.97 \\
Farming as secondary & 21.02 \\
Farming experiences: & \\
0-10 years & 11.28 \\
11-20 years & 24.35 \\
21-40 years & 51.02 \\
Above 41 years & 13.33 \\
The average distance from home to nearby market (km) & 4.12 \\
The average distance from home to UAO (km) & 5.5 \\
Member of any social organization (\%) & 14.76 \\
\hline
\end{tabular}

Note: Small farm (0.05-2.19 acre), Medium farm (2.50-7.49 acre), and Large farm (7.50 to above).

Source: BBS, 2020

\subsection{Performance of BRRI Developed Aus rice Varieties}

Table 3 shows that Aus rice was cultivated in the most
Upazilas of Mymensingh district except Gouripur Upazila. Recently, the farmers have been encouraged to expand the area under Modern Varieties (MVs) by incentive programs for Aus cultivation that will ultimately reduce the pressure on underground water for Boro production. Therefore, the adoption of MVs in the Aus season is gradually increasing. The overall adoption of modern varieties in the Aus season was about $100 \%$ of which the coverage of BRRI varieties was about $84 \%$. Among all BRRI varieties, BRRI dhan 28 ranked the top position (25\%) in terms of area coverage followed by BRRI dhan48 (23\%), and BR26 (16\%). Adoption of BRRI dhan 48 in some Upazilas ranged from 19 to $37 \%$, while adoption of the variety in some Upazilas namely Dhobaura, Haluaghat, Muktagacha, and Trishal was low (4-11\%). Besides, the adoption of BRRI dhan28 ranged between $43-52 \%$ of the total Aus area of Fulbaria, Muktagacha, and Trishal. Similarly, the adoption of Nerica was notable in Haluaghat (36\%) and the adoption of BR3 was about $76 \%$ of the total Aus area of Dhobaura Upazila (Table 3). It can be noted that the adoption of recently released $A u s$ varieties, like BRRI dhan55, BRRI dhan65, BRRI dhan82, and BRRI dhan85 was not found at the farm level in the study areas because of unavailability of the seed of those varieties.

Table 3. Adoption status (\%) of Aus rice varieties in Mymensingh district.

\begin{tabular}{|c|c|c|c|c|c|c|c|c|}
\hline \multirow{2}{*}{ Varieties } & \multicolumn{8}{|c|}{ Upazilas } \\
\hline & 1 & 2 & 3 & 4 & 5 & 6 & 7 & 8 \\
\hline BR1 & - & - & - & - & - & - & 4.55 & - \\
\hline $\mathrm{BR} 2$ & - & - & - & - & - & - & 5.45 & - \\
\hline BR3 & 75.91 & 2.81 & 28.57 & - & - & 22.54 & 7.27 & - \\
\hline BR14 & - & - & - & - & - & 2.79 & 13.64 & - \\
\hline BR16 & - & - & - & - & - & 1.76 & 2.91 & - \\
\hline BR26 & 7.77 & 12.28 & 42.86 & 13.93 & - & 9.22 & 25.45 & 41.05 \\
\hline BRRI dhan28 & 3.11 & 43.33 & - & 6.83 & - & 15.57 & 18.18 & 52.63 \\
\hline BRRI dhan43 & - & 6.32 & - & - & - & 1.02 & 1.82 & - \\
\hline BRRI dhan48 & 7.77 & 33.33 & 28.57 & 30.05 & - & 11.27 & 19.09 & 4.21 \\
\hline All BRRI Varieties & 94.56 & 98.07 & 100 & 50.82 & - & 64.18 & 98.36 & 97.89 \\
\hline Faizer & - & 1.93 & - & 49.18 & - & - & - & - \\
\hline Nerica & 5.44 & - & - & - & - & 35.82 & 1.64 & 2.11 \\
\hline Other MVs & 5.44 & 1.93 & - & 49.18 & - & 35.82 & 1.64 & 2.11 \\
\hline
\end{tabular}

Table 3. Continued.

\begin{tabular}{|c|c|c|c|c|c|c|}
\hline \multirow{2}{*}{ Varieties } & \multicolumn{5}{|c|}{ Upazilas } & \multirow{2}{*}{ Mymensingh } \\
\hline & 9 & 10 & 11 & 12 & 13 & \\
\hline BR1 & - & - & - & - & - & 0.15 \\
\hline BR2 & - & - & - & - & - & 0.20 \\
\hline BR3 & - & - & - & - & - & 13.11 \\
\hline BR14 & - & - & - & - & - & 0.88 \\
\hline BR16 & 3.94 & - & - & - & - & 0.67 \\
\hline BR26 & 6.30 & 27.27 & - & 29.91 & 31.25 & 15.67 \\
\hline BRRI dhan27 & 0.79 & - & - & - & - & 0.06 \\
\hline BRRI dhan28 & 17.32 & 27.27 & - & 51.66 & 18.75 & 24.99 \\
\hline BRRI dhan43 & - & - & - & 5.44 & - & 2.42 \\
\hline BRRI dhan48 & 70.87 & 36.36 & 100 & 11.18 & 37.50 & 23.89 \\
\hline All BRRI Varieties & 99.21 & 90.91 & 100 & 98.19 & 87.5 & 82.04 \\
\hline Faizer & - & - & - & - & 8.75 & 11.42 \\
\hline
\end{tabular}




\begin{tabular}{lllllll}
\hline \multirow{2}{*}{ Varieties } & Upazilas & & & & & M \\
\cline { 2 - 6 } & $\mathbf{9}$ & $\mathbf{1 0}$ & $\mathbf{1 1}$ & $\mathbf{1 2}$ & $\mathbf{1 3}$ & \multicolumn{2}{c}{ Mymensingh } \\
\hline Nerica & 0.79 & 9.09 & - & 1.81 & 3.75 & 1.54 \\
Other MVs & 0.79 & 9.09 & - & 1.81 & 12.50 & 17.96 \\
Grand Total & 100 & 100 & 100 & 100 & 100 & 100 \\
\hline
\end{tabular}

Note: 1) Dhobaura; 2) Fulbaria; 3) Fulpur; 4) Goforgaon; 5) Gouripur; 6) Haluaghat; 7) Ishargonj; 8) Muktagacha; 9) Nandail; 10) Sadar; 11) Tarakanda; 12) Trishal; 13) Valuka. Source: Analyzed and prepared by authors based on the data from DAE, 2018.

Table 4 represents the per hectare yield of adopted varieties in different Upazilas of Mymensingh district. In the Aus season, BRRI dhan48 produced the highest yield (4.35 ton/ha) followed by Nerica (4.19 t/ha) and BRRI dhan28
(4.12 ton/ha) in the study areas. The average yield of BRRI varieties and all MVs were $4.05 \mathrm{t} / \mathrm{ha}$ and $4.09 \mathrm{t} / \mathrm{ha}$, respectively (Table 4).

Table 4. Yield (t/ha) of Aus rice varieties in Mymensingh district.

\begin{tabular}{|c|c|c|c|c|c|c|c|c|c|c|c|c|c|}
\hline \multirow{2}{*}{ Varieties } & \multicolumn{12}{|c|}{ Upazilas } & \multirow{2}{*}{ Mymensingh } \\
\hline & 1 & 2 & 3 & 4 & 6 & 7 & 8 & 9 & 10 & 11 & 12 & 13 & \\
\hline BR1 & - & - & - & - & - & 4.00 & - & - & - & - & - & - & 4.00 \\
\hline $\mathrm{BR} 2$ & - & - & - & - & - & 3.88 & - & - & - & - & - & - & 3.81 \\
\hline BR3 & 3.87 & 4.78 & 3.73 & - & 4.22 & 3.92 & - & - & - & - & - & - & 4.08 \\
\hline BR14 & - & - & - & - & 4.25 & 3.94 & - & - & - & - & - & - & 4.10 \\
\hline BR16 & - & - & - & - & 4.35 & 3.92 & - & 3.73 & - & - & - & - & 4.00 \\
\hline BR26 & 3.73 & 4.26 & 3.70 & 3.73 & 4.90 & 3.96 & 4.48 & 3.66 & 3.51 & - & 3.70 & 4.18 & 3.98 \\
\hline BRRI dhan 28 & 3.81 & 4.10 & - & 3.93 & 5.60 & 3.88 & 4.48 & 3.88 & 3.88 & - & 3.76 & 3.88 & 4.12 \\
\hline BRRI dhan43 & - & 4.25 & - & - & 4.06 & 3.88 & - & - & - & - & 3.73 & - & 3.98 \\
\hline BRRI dhan48 & 4.03 & 4.33 & 4.18 & 4.18 & 5.42 & 3.99 & 4.45 & 4.48 & 4.61 & 3.73 & 4.11 & 4.03 & 4.35 \\
\hline All BRRI Varieties & 3.86 & 4.34 & 3.87 & 3.95 & 4.74 & 3.93 & 4.47 & 3.90 & 4.00 & 3.73 & 3.83 & 4.03 & 4.05 \\
\hline Faizer & - & 4.61 & - & 3.88 & - & - & - & - & - & - & - & 3.62 & 4.04 \\
\hline Nerica & 3.88 & - & - & - & 4.6 & 3.65 & 4.85 & 4.03 & 4.01 & - & 3.51 & 4.98 & 4.19 \\
\hline All other MVs & 3.88 & 4.61 & & 3.88 & 4.6 & 3.65 & 4.85 & 4.03 & 4.01 & & 3.51 & 4.3 & 4.13 \\
\hline
\end{tabular}

Note: 1) Dhobaura; 2) Fulbaria; 3) Fulpur; 4) Goforgaon; 5) Gouripur; 6) Haluaghat; 7) Ishargonj; 8) Muktagacha; 9) Nandail; 10) Sadar; 11) Tarakanda; 12) Trishal; 13) Valuka. Source: Analyzed and prepared by authors based on the data from DAE, 2018.

\subsection{Criteria and Constraints of Most Popular Aus Varieties}

Most farmers felt in FGD that shorter growth duration, seed availability, higher market price, good taste for eating, and less pest infestation were the key drivers of BRRI dhan 28 being adopted in the Aus season. Similarly, the main reasons for the adoption of BRRI dhan48 were good yield potential, lodging tolerant, higher market demand, less bird attack due to erect flag leaf, and easy availability of seed from DAE. In addition, the key drivers of adoption BR26 were higher yield potential, less sterility/fewer unfilled grains, and the use of seed at the household level. Farmers confirmed, however, that cooked BR26 rice becomes soft within a short time frame. Farmers recorded that pest and weed infestation was very strong at $A u s$ season, as this season very few growers sporadically used to grow rice in their fields.

\subsection{Factors Affecting Adoption of BRRI Varieties}

The outcome of the censored regression in Table 5 showed that as predicted, several of the variables influence the likelihood of adoption. For the estimation, the model has included factors, which were presumed to facilitate in setting the adoption decisions of alternative rice varieties. The variables selected were socio-cultural factors, information access, and varietal specific features. Also checked multicollinearity and heteroscedasticity for the estimation of the best parameters. Multicollinearity does not affect the estimation of the best parameters at all. Heteroscedasticity was detected in the dataset, however, and the 'Robust' command on STATA was used to stamp out that problem. The $\mathrm{F}$ value also implied the degree of fitness of the model and the present model shows a higher level of significance overall.

Factors that positively and significantly influence the adoption of BRRI varieties include education marginal and small farm size, training, distance to the local market, price variation, taste, number of variety cultivated, and yield variation. Results showed that an increase in the education of farmers raises the probability of adoption of BRRI varieties. The result reveals that the more educated the farmer, the more likely would be to adopt BRRI varieties, presumably because he can process more knowledge easily than others. This result is consistent with earlier literature Langyintuo and Mungoma, Kassie et al, Asfaw et al, and Ghimire et al [2326]. The positive and significant sign-on farm size indicated that as farm size increased the probability of farmers adopting and intensifying the BRRI varieties increased. Such findings are compatible with Danso-Abbeam et al, Mariano et al, Ghimire et al and Islam et al [26-29]. 
Table 5. Estimation of Tobit model for determinants of adoption of BRRI Aus varieties in Mymensingh district, ( $n=390)$.

\begin{tabular}{lll}
\hline Variables & Tobit Coefficient $\mathbf{H}^{\#)}$ & Marginal effect dy/dx \\
\hline Socio-demographic variables: & & 0.61 \\
Age & $0.680^{\mathrm{NS}}(0.82)$ & $1.435^{*}$ \\
Education & $1.587^{*}(1.79)$ & $0.011^{\mathrm{NS}}$ \\
Household size & $0.122^{\mathrm{NS}}(0.38)$ & $23.245^{* *}$ \\
Farm size & $30.231^{* *}(2.47)$ & $1.001^{* *}$ \\
Access to information: & $1.321^{* *}(2.15)$ & $-1.589^{*}$ \\
Training & $-2.756^{*}(-1.90)$ & $-0.532^{\mathrm{NS}}$ \\
Distance to local market & $-0.737^{\mathrm{NS}}(-0.51)$ & $4.786^{* *}$ \\
Distance to UAO & $7.122^{* *}(2.23)$ & $5.465^{* * *}$ \\
Price variation & & $1.918^{*}$ \\
Varietal specific characteristics: & $9.612^{* * *}(3.21)$ & $7.654^{* * *}$ \\
Taste and preference & $2.125^{*}(1.88)$ & \\
Varieties number & $12.321^{* * *}(2.92)$ & \\
Yield variation & $98.421^{* * *}(2.85)$ & \\
Constant & -87.607 & 103.291 \\
Log pseudo-likelihood value & $0.000^{* * *}$ & \\
Sigma & 0.312 & \\
Prob $>\mathrm{F}$ & & \\
Pseudo R & & \\
\hline
\end{tabular}

Note: \#) means robust standard errors are calculated $\mathrm{t}$ statistics in parentheses and $* * *$ and $* * *$ imply statistical significance at $10 \%, 5 \%$, and $1 \%$ levels, respectively.

Training helps farmers to gain realistic know-how for new technology and technical information. Participation in the training has had a significant and positive effect on the adoption of BRRI rice cultivars. The finding is conformity with Teshome et al and Takam-Fongang et al results [30, 31]. Reducing the gap to the UAO and local market, however, had a major and optimistic impact on BRRI variety choices. That is because the transaction cost of obtaining varietal information and marketing their goods to the local market is minimized by a lesser distance. These findings are in agreement with Mondo et al results [32]. Paddy price is always a bigger factor of farm revenue and extensively responsible for BRRI varieties being adopted.

Additionally, positive and significant coefficients indicate that the adoption decision of more BRRI varieties highly depends on the quality of rice and good taste. The results are similar to the findings of Timu et al and Otieno et al [33, 34]. The number of verities coefficients was positive and statistically significant, meaning more varieties give farmers more options to choose from. This suggests more BRRI varieties should increase the coverage of the area to them. The model exposed that yield variation was positive and influenced statistically to significantly increase the area coverage of BRRI varieties in the field of the farmer. Similar results were reported by Ghimire et al and Timu et al [26, 33]. Finally, it was commented that the possibility of a higher yield of any variety of rice might easily inspire the farmers to increase the variety's area coverage.

\section{Conclusion and Recommendation}

Adopting modern varieties for cultivation is important to meet the food demand of the growing population. The availability of quality seed and region-specific cultivars will also enhance the rice growers' adoption decisions. This study assessed the level of adoption and yield; criteria and constraint, as well as determinants of adoption and the intensity of adoption of BRRI, released Aus cultivars in Mymensingh district. The majority of farmers in Aus season cultivated BRRI cultivars due to shorter growth duration, availability of quality seed, higher market price, lodging resistance, good taste, and less infestation of pests. The largest portion is planted to BRRI dhan28, accompanied by BRRI dhan48, BRRI dhan26, and BR3. Though BRRI dhan48 yielded higher followed respectively by BRRI dhan28, BR14, and BR3. Alternatively, some of the BRRI Aus cultivars lose reputation among farmers because of lower yields and pest attacks. This research also examined the factors that affect the adoption and intensity of adoption of Aus cultivars of BRRI. Tobit censored regression econometric model was implemented for the study and the empirical findings revealed that schooling, farm size, training, price variation, yield variation, taste and preference, and distance to the local market significantly and positively affected BRRI cultivars' decision to adopt, while age, household size and distance to UAO had no significant impact on the decision to adopt.

The policy implication of this study is that breeders should also concentrate on non-yield traits such as taste, fine grain, and hold cooked rice for longer periods in their efforts to develop new Aus varieties since they are very important in explaining the high adoption BRRI varieties. Secondly, the availability of quality seeds of recently introduced BRRI cultivars should be ensured for farmers. Thus, this requires enormous cooperation between BRRI, DAE, BADC, and other seed producers to deliver the required quality seed to the farmers.

\section{Abbreviations}

BRRI=Bangladesh Rice Research Institute, HYV=High Yielding Variety, DAE=Department of Agricultural 
Extension, BADC $=$ Bangladesh Agricultural Development Corporation, $\mathrm{UAO}=$ Upazila Agriculture Officer, SAAO $=$ Sub-Assistant Agriculture Officer, $F G D=$ Focus Group Discussion.

\section{Funding}

The author (s) received no financial support for the research, authorship, and/or publication of this article.

\section{Ethics Approval and Consent to Participate}

All survey participants obtained clear oral informed consent before the survey enumeration and recorded as the opening question after reminding survey participants regarding the intent of the research. When permission was refused, enumeration of the sample was canceled.

\section{Consent for Publication}

Every author accepts and consents to publish the manuscript.

\section{Conflict of Interest Statement}

All the authors do not have any possible conflicts of interest.

\section{Acknowledgements}

The authors are indebted to the all UAO office of the Mymensingh district for supplying the list of the farmers and help to conduct FGDs. We appreciate all the respondents who took part in the study too.

\section{References}

[1] Chowdhury, M. A. (2009). Sustainability of accelerated rice production in Bangladesh: technological issues and the environment. Bangladesh Journal of Agricultural Research, 34 (3), 523-529.

[2] BBS "Yearbook of Agricultural Statistics-2019", Statistics and Informatics Division, Bangladesh Bureau of Statistics, Ministry of Planning, Government of the People's Republic of Bangladesh, Dhaka, Bangladesh, 2020.

[3] BBS "Labour Force Survey of Bangladesh 2016-17", Statistics and Informatics Division, Bangladesh Bureau of Statistics, Ministry of Planning, Government of the People's Republic of Bangladesh, Dhaka, Bangladesh, 2018.

[4] Rahman, N. M. F., M. M. Hasan, M. I. Hossain, M. A. Baten, S. Hosen, M. A. Ali, and M. S. Kabir (2016). Forecasting Aus Rice Area and Production in Bangladesh using Box-Jenkins Approach. Bangladesh Rice Journal, 20 (1), 1-10.

[5] BBS "Final Report on Household Income and Expenditure Survey 2016", Statistics and Informatics Division, Bangladesh
Bureau of Statistics, Ministry of Planning, Government of the People's Republic of Bangladesh, Dhaka, Bangladesh, 2019.

[6] Bhuiyan, N. I., D. N. R. Paul, and M. A. Jabber (2002) Feeding the extra millions by 2025: Challenges for rice research and extension in Bangladesh. In National Workshop on Rice Research and Extension in Bangladesh, Bangladesh Rice Research Institute, Gazipur (pp. 29-31).

[7] Hossain, M., F. Naher, and Q. Shahabuddin (2005). Food security and nutrition in Bangladesh: progress and determinants. eJADE: electronic Journal of Agricultural and Development Economics, 2 (853-2016-56126), 103-132.

[8] S. Huq, J. Chow, A. Fenton, C. Stott, J. Taub, and H. Wright, eds. Confronting Climate Change in Bangladesh: Policy Strategies for Adaptation and Resilience. Vol. 28. Springer, 2019.

[9] Uddin, M. T. and A. R. Dhar (2018). Government input support on Aus rice production in Bangladesh: impact on farmers' food security and poverty situation. Agriculture \& Food Security, 7 (1), 14.

[10] Shelley, I. J., M. Takahashi-Nosaka, M. Kano-Nakata, M. S. Haque, \& Y. Inukai (2016). Rice cultivation in Bangladesh: present scenario, problems, and prospects. Journal of International Cooperation for Agricultural Development, 14 (4), 20-29.

[11] Khanom, T. (2016). Effect of salinity on food security in the context of interior coast of Bangladesh. Ocean \& Coastal Management, 130, 205-212.

[12] Islam, M. S., T. H., Miah, Rahman, K. M., \& Haque, M. M. 2010. Changing Land Use Patterns and Their Impact on Food Security for Farm Households in Bangladesh. National Food Policy Capacity Strengthening Programme.

[13] Afroz, S., and M. S. Islam (2012). Economics of Aus Rice (Oryza sativa) and Jute (Corchorusolitorius) Cultivation in Some Selected Areas of Narsingdi District of Bangladesh. The Agriculturists, 10 (2), 90-97.

[14] BRRI (Bangladesh Rice Research Institute), Government of the People's Republic of Bangladesh, Joydebpur, Gazipur, Bangladesh, 2011.

[15] Hussain, S. G. (2011). Assessing Impacts of Climate Change on Cereal Production and Food Security in Bangladesh. In R. Lal, A. H. M. M. Rahman, M. V. K. Sivakumar, K. R. Islam, \& S. M. A. Faiz (Eds.), Climate Change and Food Security in South Asia, pp. 459-476). Netherlands: Springer.

[16] Rahaman, M., M. A. R. Sarkar, L. Deb, M. J. Kabir, M. R. Sarker, M. Siddique, and A. B. Siddique (2018). Economic investigation of BRRI dhan 29 and hybrid rice production in Bangladesh: The case of Haor area. International Journal of Natural and Social Sciences, 5 (1), 35-43.

[17] Ellis, F. (1992). Agricultural policies in developing countries. Cambridge university press.

[18] BRRI "Modern Rice Cultivation (Adhunik Dhaner Chash)", 23rd edition, page 103. Bangladesh Rice Research Institute, Gazipur, Bangladesh, 2020.

[19] Ilesanmi, J. O., and J. A. Afolabi (2020). Determinants of Adoption of Improved Cocoa Technologies in Ekiti State, Nigeria. International Journal of Agricultural Economics, 5 (2), 36. 
[20] Feder, G., R. E. Just and D. Zilberman (1985). Adoption of agricultural innovations in developing countries: A survey. Economic development and cultural change, 33 (2), 255-298.

[21] Splett, N. S., P. J. Barry, B. L. Dixon, and P. N. Ellinger (1994). A joint experience and statistical approach to credit scoring. Agricultural finance review (USA), 54: 39-54.

[22] Johnston, J. and J. Dinardo (1997). Econometrics Methods. Fourth Edition. The McGraw-Hill Companies, Inc, New York.

[23] Langyintuo, A. S., and C. Mungoma (2008). The effect of household wealth on the adoption of improved maize varieties in Zambia. Food policy, 33 (6), 550-559.

[24] Kassie, M., B. Shiferaw and G. Muricho (2011). Agricultural technology, crop income, and poverty alleviation in Uganda. World Development, 39 (10), 1784-1795.

[25] Asfaw, S., B. Shiferaw, F. Simtowe, and L. Lipper (2012). Impact of modern agricultural technologies on smallholder welfare: Evidence from Tanzania and Ethiopia. Food policy, 37 (3), 283-295.

[26] Ghimire, R., H. U. A. N. G. Wen-Chi, \& R. B. Shrestha (2015). Factors affecting adoption of improved rice varieties among rural farm households in Central Nepal. Rice Science, $22(1), 35-43$

[27] Danso-Abbeam, G., J. A. Bosiako, D. S. Ehiakpor, and F. N. Mabe (2017). Adoption of improved maize variety among farm households in the northern region of Ghana. Cogent Economics \& Finance, 5 (1), 1416896.

[28] Mariano, M. J., R. Villano, and E. Fleming (2012). Factors influencing farmers' adoption of modern rice technologies and good management practices in the Philippines. Agricultural Systems, 110, 41-53.
[29] Islam, M. A., M. C. Rahman, M. A. R. Sarkar, and M. A. B. Siddique (2019). Assessing Impact of BRRI Released Modern Rice Varieties Adoption on Farmers' Welfare in Bangladesh: Application of Panel Treatment Effect Model. Bangladesh Rice Journal, 23 (1), 1-11.

[30] Teshome, B., R. Negash, and A. Shewa (2019). Determinants of adoption of improved Jalenea potato variety: The case of Chencha Woreda, Southern Ethiopia.

[31] Takam-Fongang, G. M., C. B. Kamdem, and G. Q. Kane (2019). Adoption and impact of improved maize varieties on maize yields: Evidence from central Cameroon. Review of Development Economics, 23 (1), 172-188.

[32] Mondo, J. M., A. B. Irenge, R. B. B. Ayagirwe, P. M. Dontsop-Nguezet, K. Karume, E. Njukwe, S. M. Mapatano, P. M. Zamukulu, G. C. Basimine, E. M. Musungayi, H. K. Mbusa, L. M. Kazamwali, R. Civava, and G. N. Mushagalusa (2019). "Determinants of Adoption and Farmers' Preferences for Cassava Varieties in Kabare Territory, Eastern Democratic Republic of Congo." American Journal of Rural Development, vol. 7, no. 2: (44-52. doi: 10.12691/ajrd-7-2-1.

[33] Timu, A. G., R. Mulwa, J. Okello, and M. Kamau (2014). The role of varietal attributes on adoption of improved seed varieties: the case of sorghum in Kenya. Agriculture \& Food Security, 3 (1), 9.

[34] Otieno, Z., J. J. Okello, R. Nyikal, A. Mwang'ombe, and D. Clavel (2011). The role of varietal traits in the adoption of improved dryland crop varieties: The case of pigeon pea in Kenya. African Journal of Agricultural and Resource Economics, 6 (311-2016-5587). 